\title{
A (IN)VISIBILISADE DO MENOR SOB GUARDA E A PENSÃO POR MORTE
}

\author{
Renata Osório Caciquinho Bittencourt* \\ Marcelo Fernando Borsio** \\ Luiz Henrique Paiva Pires ${ }^{* * *}$
}

\section{RESUMO}

A proteção social do menor sob guarda no cenário Brasileiro, em análise dos fluxos e refluxos legislativos entremeados a polêmica dos antagônicos argumentos são o objeto da presente pesquisa, desenvolvida pelo método teórico propositivo. Justifica-se a relevância a partir da necessidade de análise (in)conformidade da legislação posta com as Garantias Constitucionais com o objetivo de verificar o alinhamento a busca da Justiça Social delineada por John Rawls. Conclui-se que, mesmo com a decisão do STF garantindo a proteção social ao menor sob guarda, a persistência da polêmica demonstra a necessidade de uma profunda mudança cultural paradigmática.

PALAVRAS-CHAVES: Proteção social. Menor sob guarda. Garantias Constitucionais. Justiça Social. John Rawls.

\section{THE (IN)VISIBILITY OF THE MINOR UNDER GUARD AND THE PENSION FOR DEATH}

\footnotetext{
*Advogada. Professora na Universidade Paulista (2013 - atual). Mestranda pelo UDF em Direito das Relações Sociais e Trabalhistas. Pós-Graduada em Direito do Trabalho, Processo do Trabalho e Direito Previdenciário. Assessora Especial de Direito do Trabalho e associada da Associação Brasileira de Mulheres de Carreira Jurídica (ABMCJ). Representante da Federação Internacional das Mulheres de Carreira Jurídica na Organização Internacional do Trabalho (OIT). Email: renatacaciquinho@hotmail.com.

** Professor Titular do UDF no Curso de Mestrado em Direito das Relações Sociais e Trabalhistas, nos créditos de Direito da Seguridade Social e Previdenciário. Pós-Doutor em Direito da Seguridade Social e Professor Visitante, sob a orientação do Prof. José Luís Tortuero Plaza, pela Universidade Complutense de Madrid (2014). Pós-Doutor em Direito Previdenciário e Professor Visitante, sob a orientação do Professor Giuseppe Ludovico, pela Universidade de Milão (2017). Pós-Doutorando em Direito Previdenciário pela UERJ, com o Prof. Dr. Fábio Zambitte Ibrahim. Doutor (2013) e Mestre (2007) em Direito Previdenciário pela Pontifícia Universidade Católica de São Paulo. Especialista em Limites Constitucionais da Investigação pela Univ. Santa Catarina. Especialista em Direito Tributário pela PUC-SP. Graduação em Direito pela Universidade Presbiteriana Mackenzie. Ex-Professor e Ex-Coordenador da Pós-Graduação de Direito Previdenciário na Rede LFG. ExProfessor e Ex-Coordenador do Curso de Prática Previdenciária na Rede LFG. Professor Convidado da PósGraduação da PUC-SP (COGEAE). Professor de Direito Previdenciário da Pós-Graduação em Direito Previdenciário e Preparatório para Magistratura do Trabalho e Procurador do Trabalho na ATAME -DF. Professor convidado na Pós-Graduação de Direito Previdenciário na Faculdade Baiana - Salvador. Editor Assistente da Revista Direito das Relações Sociais e Trabalhistas da Faculdade de Direito do UDF. Avaliador de artigos da Revista Jurídica da Presidência da República. Delegado de Polícia Federal aposentado e ex-integrante da Força-Tarefa Previdenciária e DELEPREV, em combate às fraudes previdenciárias. Membro da Asociación Española de Salud y Seguridad Social. Membro fundador da Academia Brasileira de Direito da Seguridade Social, titular da cadeira n 15. Presidente do Conselho de Recursos da Previdência Social de fevereiro de 2019 até agosto de 2021. Atualmente Assessor de Assuntos Estratégicos da Presidência do INSS. Integrante do Comitê de Avaliação da CAPES - Área do Direito (Stricto Sensu). Membro Avaliador da CAPES na Coordenação da Área de Direito. Email: marcelo.borsio@hotmail.com.

*** Advogado. Mestrando pelo UDF em Direito das Relações Sociais e Trabalhistas. Email: luizhpaivapires@hotmail.com.
} 


\section{ABSTRACT}

Social protection of minors under custody in the Brazilian o, in the analysis of legislative ebbs and flows, interspersed with the controversy of antagonistic arguments, are object of this research, developed by the propositional theoretical method. The relevance is justified by the need to analyze (non)conformity of the legislation put in place with the Constitutional Guarantees in order to verify the alignment with the search for Social Justice outlined by John Rawls. It's concluded that, even with STF's decision guaranteeing social protection to minors in custody, the persistence of controversy demonstrates the need for a profound paradigm cultural change.

KEYWORDS: Social protection. Minor under guard. Constitutional Guarantees. Social justice. John Rawls.

\section{INTRODUÇÃO}

Os riscos sociais são inerentes a vida de todas as pessoas e, em razão disso, o ser humano buscou criar formas de minimizar as consequências negativas decorrentes. Especificamente em relação ao risco da morte, há no ordenamento jurídico brasileiro a existência do benefício pensão por morte perante o Regime Geral de Previdência, direcionado ao dependente do segurado falecido. A temática possui tom polêmico, demonstrando fluxos e refluxos legislativos, ora incluindo, ora excluindo o menor sob guarda da proteção social. Em análise legislativa recente, a Reforma da Previdência caminhou em sentido inverso da proteção das Garantias Constitucionais, excluindo o menor sob guarda dessa lista, sempre sob o argumento de afastar possíveis fraudes na concessão do benefício.

Estaria tal interpretação das legislações adequada em um âmbito jurídico-prático? Há ou não direito do menor sob guarda ao benefício da pensão por morte? E, seja quais forem as conclusões, quais os motivos determinantes de cada vertente justificam o debate, demonstrando qual deles se sobressai em um verdadeiro diálogo de fontes? Essas inquietações, aliadas a condição de limbo em que se encontrou o menor sob guarda após a Reforma da Previdência no que tange a pensão por morte de seu guardião, levaram a análise do tema pelo Supremo Tribunal Federal no ano de 2021, com resultado em votação extremamente apertada.

$\mathrm{O}$ aprofundamento dessa pesquisa que buscou em dados concretos, humanos e principiológicos, a luz da direção interpretativa de John Rawls sobre o que se tem por sociedade justa, e em atenção aos princípios da seguridade social, em especial o da solidariedade, alcançar qual vertente se amolda em plenitude a Justiça Social efetiva, preceito fundamental do Estado Democrático de Direito para verificar a (in)correção da decisão do 
Supremo Tribunal Federal ao analisar o texto da Reforma da Previdência e a sua (in)suficiência no alcance de uma mudança paradigmática cultural, mais profunda do que uma determinação de aplicação da norma por controle jurisdicional.

\section{A EXTENSÃO OU SUBSTITUIÇÃO DA FAMÍLIA E A GUARDA DO MENOR}

Qual a importância da infância na formação de uma pessoa? Quanto um ambiente estável emocionalmente, seguro e acolhedor, diferencia e ajuda e influenciar uma personalidade? Qual o lastro de proteção deve alcançar a infância? Quem protege as crianças fora da família natural? Quem protege as crianças vulneráveis? O quanto o arcabouço legal está preparado para assegurar a dignidade de todas as crianças?

O desafio de responder essas perguntas é notoriamente instigante e, mesmo que nem todas as respostas sejam objetivas, certo é que o menor é responsabilidade do Estado, da família e da sociedade, uma preocupação inclusive prevista na Constituição Humanista de 1988, especialmente em seu artigo 227. Para além, a proteção da infância está prevista na Convenção sobre os Direitos da Criança, adotada pela Assembleia da ONU em 1989 e em vigor desde 1990. Tal Convenção foi ratificada por 196 países, dentre eles o Brasil, consistindo no "instrumento de direitos humanos mais aceito na história universal" (UNICEF).

Diante dessas premissas, sendo inegável a necessidade de resguardar a infância dentro de um Contrato Social democrático e inclusivo, há que se destacar, conforme recorte desse ensaio, dentre o universo infantil, as crianças em situação de guarda em família extensa ou substituta. Em que pese o Estatuto da Criança e do Adolescente (Lei 8.906/90) primar pelo critério da consanguinidade em posição hierárquica superior a afetividade, conferindo a família natural, via regra, preferência para colocação do menor, há situações em que a mesma não se faz presente, ou mesmo, não atende aos interesses da criança, não cumprindo a sua função social e, por essa razão, sendo destituída do direito-dever de cuidar do infante.

A função social da família consiste em assegurar "ambiente saudável para o desenvolvimento de seus membros de forma digna, principalmente para os filhos menores, pois estes estão se moldando de acordo com os valores que lhe são repassados" (LANDO, CUNHA, LIMA, 2016). Quando esse encargo é descumprido há, em grau de excepcionalidade, colocação do menor em família extensa (cuidados exercidos por parentes 
mais próximos com vínculos de afinidade e afetividade), atendendo aqui a combinação de critérios de consanguinidade e afetividade ou, família substituta (aquela que inserirá a criança no seu seio através da guarda, tutela ou adoção), onde há valoração da afetividade em hierarquia superior a consanguinidade, em substituição ao sistema de abrigamento.

O menor sob guarda é a criança ou adolescente, menor de 18 anos, submetido a um poder familiar exercido por pessoa diversa dos pais, tendo em vista que, por algum motivo relevante, estes não conseguem exercer seus deveres. Destaca-se, que o natural seria então que a criança estivesse submetida ao poder familiar originário, porém, configuradas as hipóteses dos artigos 33 a 35 do Estatuto da Criança e do Adolescente, visando seu melhor interesse, sua proteção e sua dignidade, o Estado lhe redireciona a família extensa ou a família substituta, a qual tem o dever de zelar pela integridade física, psicológica e material do infante.

$\mathrm{O}$ artigo 1.584 , em seu parágrafo $5^{\circ}$ do Código Civil, estabelece que sempre que o juiz verificar ausência de cumprimento pelos pais das obrigações de zelo e proteção da criança, transferirá a guarda a pessoa compatível com o múnus, preferencialmente com laços de afetividade, afinidade e parentesco com a criança. O Estatuto da Criança e do Adolescente (Lei 8.069/90), por sua vez, em seu artigo 33, § $1^{\circ}$, prevê que também se encontra sob guarda, incidental ou liminarmente, o menor que está em posse de fato por família não originária, enquanto tramita processo judicial de adoção definitiva ou tutela, o que fita a regularização de situação jurídica posta.

Ainda na Lei 8.069/90, em seu artigo 33, § 2º há previsão de colocação do menor sob guarda, excepcionadas as hipóteses de adoção e tutela, nos casos de atendimento a situações peculiares e suprimento de eventual falta dos pais ou responsável (é o que ocorre quando os pais se ausentam para fazer uma viagem ao exterior por exemplo, ou mesmo um curso fora do país de média ou longa duração, ficando o menor em situação precária quanto a legalidade da sua proteção, bem como nos aspectos físico, afetivo e moral). Ao guardião cabe a assistência educacional, moral, afetiva e material do menor sob sua responsabilidade, tendo para tanto, a prerrogativa de impor suas decisões no que tange a criança, mesmo que em oposição a terceiros ou até aos pais naturais do infante. Nessa senda, a guarda configura-se como uma das três modalidades de extensão da família natural para substituta lato sensu, ao lado da tutela e da adoção. 
Nesse contexto tem-se por um lado as obrigações de zelo e cuidado do guardião para como o infante. Por outro, o direito do menor de ser protegido, cuidado de forma integral por quem ocupa essa função, sendo-lhe garantida a segurança necessária para que possa formar-se enquanto ser humano de maneira digna e satisfatória. E ainda, pelos dois lados, não raro, a presença do indissociável laço de amor, que os une e os identifica enquanto família, estabelecendo seu lugar na sociedade.

\section{TIRA PÕE DEIXA FICAR - A CIRANDA DA DESPROTEÇÃo PREVIDENCIÁRIA DO MENOR SOB GUARDA}

A Constituição Humanista de 1988, em uma nítida preocupação de assegurar o orientado pela Declaração Universal dos Direitos da Criança, empregou a Doutrina da Proteção Integral, conferindo aos menores direitos com status fundamentais e proteção maior do poder constituinte. No âmbito infraconstitucional, visando a necessidade de editar normas mais especificas de proteção do infante, foi promulgada a Lei 8.069 em 1990 - Estatuto da Criança e do Adolescente (ECA). O próprio ECA prevê, de forma explícita em seu artigo 33, $\S 3^{\circ}$, a condição de dependente do guardião ao menor sob guarda para todos os fins, especialmente os previdenciários, texto esse vigente desde a sua promulgação. Então qual seria a polêmica da temática?

Para entender o debate histórico legal é preciso analisar a ciranda das alterações do tema, contextualizando as justificativas utilizadas para tanto e avaliando se elas são consistentes e válidas, ou frágeis e inconstitucionais. A Lei 8.213 de 1991, a qual cuida da disposição dos Benefícios da Previdência Social relativos ao Regime Geral, em seu artigo 16, no parágrafo $2^{\circ}$, tinha redação original prevendo no mesmo sentido do ECA e da $\mathrm{CF} / 88$, ou seja, tratava o menor sob guarda de forma equiparada ao filho, dando a ele, portanto, o status de dependente previdenciário do segurado, no caso, seu guardião. Até esse momento a legislação nacional e internacional, constitucional e infraconstitucional estavam em harmonia quanto a proteção integral e prioritária desses menores, especialmente no que se refere a sua condição de dependência, inclusive previdenciária.

Porém, em novembro de 1996, a Medida Provisória 1.523 rompeu esse cenário, excluindo do rol de dependentes previstos na Lei 8.213 de 1991 o menor sob guarda. E qual era o sentido daquela mudança? Justificou-se na verificação recorrente de fraudes perante o 
sistema previdenciário. Nesse ardil, pessoas mal-intencionadas utilizavam-se da legislação que protegia o menor sob guarda quando do falecimento de seu guardião e criavam uma espécie de guarda fictícia, que não se verificava na realidade dos fatos. Tal situação era verificada, de forma recorrente, entre avós e netos, onde, presente o risco social morte do guardião fictício, o menor hipoteticamente sob guarda podia usufruir a pensão por morte (LEMOS; MENEZES, 2018).

Cerca de um ano depois, em dezembro de 1997, a referida medida provisória foi convertida na Lei 9.528, alterando definitivamente o Plano de Benefícios do Regime Geral quanto ao afastamento da dependência do menor sob guarda naquela perspectiva legal. Ocorre que se criou nesse momento uma dicotomia. Ao passo que a legislação previdenciária própria, em sua evolução, afastou o menor sob guarda da dependência do segurado, o Estatuto da Criança e do Adolescente, legislação anterior, continuou a prever a referida dependência, estando posto o embate de divergência interpretativa perante os tribunais. Nesse compasso, o tratamento não isonômico era evidente, visto que a redação legal que excluiu o menos sob guarda do rol de dependentes, manteve, a referida proteção quando ao menor tutelado e ao enteado, lhes conferindo equiparação a condição de filho (LEMOS; MENEZES, 2018).

A divergência jurisprudencial fundamentou a instituição do tema 732 do Superior Tribunal de Justiça, que teve repercussão geral reconhecida através do Resp. 1411258/RS. O ministro relator, Napoleão Nunes Maia Filho destacou a admissão do Recurso Especial como representativo da controvérsia na origem, visto a "recursos especiais com fundamento em questão idêntica de direito e em razão da diversidade de fundamentos do acórdão e dos argumentos apresentados pelo recorrente" (STJ, 2018). Para pacificar o conflito, o Superior Tribunal de Justiça deu o tom interpretativo da matéria, determinando a necessidade de interpretação em conformidade das legislações, sempre sob o crivo dos princípios, interesses e proteções constitucionais, o que, nessa temática protegeria a dependência econômica do menor sob guarda. Vejamos:

STJ. TEMA 732. Tese Firmada: O menor sob guarda tem direito à concessão do benefício de pensão por morte do seu mantenedor, comprovada sua dependência econômica, nos termos do art. 33, $\S 3^{\circ}$ do Estatuto da Criança e do Adolescente, ainda que o óbito do instituidor da pensão seja posterior à vigência da Medida Provisória 1.523/96, reeditada e convertida na Lei 9.528/97. Funda-se essa conclusão na qualidade de lei especial do Estatuto da Criança e do Adolescente (8.069/90), frente à legislação previdenciária (STJ, 2018).

A conclusão do Superior Tribunal de Justiça ao interpretar a legislação foi no sentido de que o "ECA não é uma simples lei, uma vez que representa política pública de proteção à 
criança e ao adolescente, verdadeiro cumprimento do mandamento previsto no art. 227 da CF/88" (STJ, 2018). Assim, em um conflito de normas, estabelecido o diálogo entre elas e posta a agir a ponderação, resta por prevalecer a proteção integral do menor, norma internacional, de caráter humanitário, ratificada pelo Brasil, confirmada constitucionalmente e reafirmada pelo Estatuto da Criança e Adolescente não só enquanto norma, mas especialmente enquanto política pública de proteção da dignidade humana.

Porém, a ciranda continuou, como em uma brincadeira infantil de mau gosto, sendo que a Emenda Constitucional 103/2019, intitulada Reforma Previdenciária, em seu artigo 23, $\S 6^{\circ}$, novamente veio delimitar quem são os dependentes previdenciários do segurado para fins de pensão por morte, momento em que, com o termo "exclusivamente", ao silenciar sobre o menor sob guarda, passa a excluí-lo daquela dependência, retornando-o a incerteza da desproteção firmada desde a MP 1.523/96 até a pacificação do Tema 732 pelo STJ.

Frisa-se que, em que pese a legalidade da alteração normativa no sentido formal para estabelecer regramento quanto a pensão por morte, não o é no sentido estrutural da legislação brasileira enquanto contexto, enquanto conjunto de normas. Isso porque, a involução da lei determinou um retrocesso social evidente, destoando dos pilares constitucionais em que se funda a República e conferindo ao menor sob guarda a condição de invisível, de excluído, do “não dito" na norma que o faz o não sujeito àquele direito em debate - pensão por morte.

Relegar o menor sob guarda a própria sorte exatamente no momento em que o risco social morte se faz presente em relação ao seu guardião, lhe retira a dignidade humana constitucionalmente garantida, os direitos mínimos de proteção integral a infância previstos no artigo 227 da Carta Maior e descumpre os objetivos da Declaração Internacional dos Direitos da Criança ratificada pelo Brasil. Não bastasse isso, o mundo passou a enfrentar uma crise sanitária altamente imprevisível desde 2020, causada pela pandemia da Covid-19. Nesse contexto o problema fica ainda mais evidente, visto que o risco social morte foi nitidamente incrementado pelo vírus circulante, sem, contudo, a diminuição proporcional nas causas que anteriormente balizavam esse índice. Assim, estando o fato gerador do benefício em nítida ascensão, relevante se faz atenção a exclusão do menor sob guarda, que nesse ponto histórico legal teve mitigada sua dignidade constitucionalmente garantida com o afastamento de si da pensão por morte na condição de dependente.

Porém, como dito, a ciranda continua e, felizmente, ainda há esperança de que o abandono, os interesses econômicos e a insensibilidade humana deixem de fazer frente para 
dar lugar a solidariedade, a igualdade substancial, a efetividade do Estado Democrático de Direito. Aqui cabe ressaltar o princípio da Solidariedade, que é extremamente relevante em se tratando de previdência social. Esse princípio é fundamental, sendo base para o entendimento de como funciona a seguridade social no Brasil. De acordo com Frederico Amado (2016):

Essencialmente a seguridade social é solidária, pois visa a agasalhar as pessoas em
momentos de necessidade, seja pela concessão de um benefício previdenciário ao
segurado impossibilitado de trabalhar (previdência), seja pela disponibilização de um
medicamento a uma pessoa enferma (saúde) ou pela doação de alimentos a uma
pessoa em estado famélico (assistência). Há uma verdadeira socialização dos riscos
com toda a sociedade, pois os recursos mantenedores do sistema provêm dos
orçamentos públicos e das contribuições sociais, onde aqueles que pagam tributos que
auxiliam no custeio da seguridade social, mas hoje ainda não gozam dos seus
benefícios e serviços, poderão no amanhã ser mais um dos agraciados, o que traz uma
enorme estabilidade jurídica no meio da sociedade.

Excluir o menor sob guarda do rol de dependentes da pensão por morte é o avesso da determinação solidária previdenciária constitucional, pois nega a essas crianças dignidade humana e direitos sociais exatamente quando se faz presente o risco social para o qual o segurado falecido contribuiu ao sistema. O mal não pode ser pressuposto, especialmente na formulação da legislação. Não pode o legislador, sob a escusa de evitar a fraude, criar situação de exclusão de direitos e de tratamento não isonômico. Cabe ao Estado evitar o mal por meio de educação e coerção, e não colocando o sujeito à margem da sociedade.

Excluir o menor sob guarda da proteção previdenciária entendendo a necessidade de proteção ao sistema financeiro que o sustenta é uma evidente inversão de valores. Os direitos servem as pessoas, essa é a lógica da sociedade. O Estado zela (ou assim deve ser) pelo cumprimento dos direitos, inclusive, no que se refere a sua implementação. Nesse sentir, o Supremo Tribunal Federal analisou em junho de 2021 a matéria, por meio do julgamento conjunto da $\mathrm{ADI} \mathrm{n}^{\circ} 4.878$ e da $\mathrm{ADI} \mathrm{n}^{\circ}$ 5.083, sob a relatoria do ministro Gilmar Mendes. Em votação apertada (placar de 6 contra 5) foi vencida a tese do relator, que pretendia manter a exclusão do menor sob guarda da dependência do segurado sob justificativa de proteção orçamentária diante de possíveis fraudes. Venceu a tese divergente, manifestada pelo ministro Edson Fachin (STF, 2021).

No voto de divergência destacou-se que a exclusão do menor sob guarda da proteção previdenciária na condição de dependente é incoerente com as garantias constitucionais da Carta de 1988 as crianças e adolescentes, consistindo em "insustentável retrocesso no quadro de promoção e de proteção nacional e internacional à infância e à juventude" (STF, 2021). Pontuou que o argumento de afastamento de possíveis fraudes não evita a 
inconstitucionalidade da norma e não respalda sua redação, devendo ser verificada por meios próprios. Concluiu pelo dever do Estado e da sociedade na proteção da Dignidade Humana dessas crianças, julgando "de modo a conferir interpretação conforme ao $\S 2^{\circ}$ do art. 16, da Lei 8.213/1991, para contemplar, em seu âmbito de proteção, o "menor sob guarda" (STF, 2021).

O julgamento do STF demonstra verdadeira conquista na efetivação dos Direitos e Garantias Fundamentais do Estado Constitucional Humanista conferido pela CF/88. Nesse mesmo sentido, considerando o cenário pandêmico que permeia a análise da proteção social do menor sob guarda, fez o STF interpretação resguardando os preceitos constitucionais e conforme a Organização Internacional do Trabalho que ressalta como via única para superação da crise aprofundada pela Covid-19, a efetivação de sistemas de proteção social abrangentes, ante aos impactos extremamente desiguais entre as pessoas sugerindo como resposta que os "formuladores de políticas públicas precisam aproveitar o momento gerado pela crescente conscientização pública sobre a importância da proteção social e a urgência de investir nela como sociedade, para garantir capacidade de resposta em futuras crises" (OIT Brasília, 2020).

O resultado do julgamento das mencionadas Ações Diretas de Inconstitucionalidade restabeleceram o Estado Democrático de Direito quanto a proteção das crianças ou adolescentes sob guarda, porém, o histórico egoístico da construção legislativa, baseado na exclusão do indivíduo da proteção social para evitar a necessidade e o dever de fiscalização do descumprimento da norma determinam a urgência de uma abordagem profunda do tema no sentido de convencimento dos formadores de políticas pública da natureza Constitucional imutável de tal garantia social. Sendo assim, a decisão do STF consiste em inegável avanço, mas não finda a discussão, sendo a polêmica do tema demonstrada pelo próprio placar da referida decisão, o qual demonstra acirrada divergência.

Afastar políticas públicas que releguem o menor sob guarda a uma condição de segunda categoria, de sub-filho, está para além do controle jurisdicional da norma vigente, perpassando pela necessidade de afastar a cultura do invisível, efetivando em cada pessoa que a efetivação da igualdade substancial espraia efeitos para todos e não apenas para aqueles diretamente atendidos pelas políticas públicas de equilíbrio do Contrato Social.

\section{JUSTIÇA SOCIAL E A CULTURA DO INVISÍVEL}


O menor sob guarda é uma criança (nesse ensaio trataremos todos por esse termo, independentemente da idade) que possui, no mínimo, uma história com caráter traumático. Não sob o aspecto dramático do termo, mas no sentido de que para entrar nessa categoria é necessário que o infante seja retirado da família original, do que é senso comum, do que é esperado dele enquanto posição social padrão. O abalo dos laços sociais e afetivos originários, a mudança prática na rotina, a necessidade óbvia de adaptação a um novo contexto são exposições que afetam o desenvolvimento físico e psicológico de uma criança, em especial por sua condição de pessoa em desenvolvimento e formação.

Ao ser colocado na condição de guarda é dever do guardião proteger a criança e é direito da criança se sentir protegido. Essa dinâmica posta em prática estabelece vínculos extremamente sólidos entre quem cuida e quem é cuidado, levando a natural estabilização da dependência em um sentido legal, em um processo dinâmico de identidade, pertencimento e filiação. A Constituição Federal em seu artigo 227, § $3^{\circ}$, II estabelece que é dever da família, da sociedade e do Estado e proteção especial da criança sob o aspecto previdenciário e trabalhista, dentre tantas outras vertentes de proteção desse menor, estabelecendo, portanto, um direito social amplo.

Nesse contexto, ao retirar do menor sob guarda o direito a pensão por morte estava a se cumprir o objetivo maior de Justiça Social? Para além de uma obrigação, tem-se na existência digna de todos um compromisso compulsório da Sociedade e do Estado que, para ser alcançado necessita do "abandono do tão difundido jogo do empurra-empurra, que assola o cenário político nacional, mediante a sua substituição por uma lógica da cooperação e do diálogo" (SARLET, 2008).

Nesse sentido ensina Fábio Zambitte Ibrahim (2010), que "mais do que um bônus, a garantia necessária da vida digna é um ônus social, já que a dignidade da pessoa humana é também um dever de todos para com todos". O guardião é quem supre as necessidades do menor em todos os aspectos e, em sendo o menor seu dependente econômico em vida, não existe motivo para que, quando da morte do segurado, se coloque o menor sob guarda em situação de exclusão, em um limbo legal, onde não tem mais nem família original, nem família substituta (na modalidade de direitos decorrentes), agindo o STF corretamente na declaração de inconstitucionalidade de interpretação diversa. 
A justificativa de afastamento de fraudes, proteção do equilíbrio financeiro ou qualquer outra que venha a ser utilizada não devem subsistir, visto que a Justiça Social somente será alcançada caso se afaste dos valores egoísticos e se aproxime dos valores humanos, havendo que se ter "coragem, humildade, amor ao próximo, honra e compromisso com o futuro da humanidade, para o desapego com o material e o lucro obsceno" (BORSIO, 2017). O menor sob guarda, ao ser silenciado do texto da emenda constitucional, aliado ao termo "exclusivamente", que estabeleceu rol taxativo para equiparação a filho no contexto de dependente previdenciário, passou ao que vamos chamar de cultura do invisível, que consiste em ignorar a sua existência enquanto cidadão sujeito de direitos fundamentais, impedindo a concretização da Justiça Social.

O STF corrigiu tamanha injustiça, porém, considerando a polêmica ainda existente nas discussões acadêmicas e legislativas, há que ultrapassar o controle constitucional realizado, debatendo o tema a fim de demonstrar o necessário olhar humanista constitucional para a matéria em uma mudança cultural, onde o indivíduo esteja sempre a frente de qualquer outro interesse, em contrassenso ao neoliberalismo que empunha a bandeiro do "eu sozinho tudo posso", demonstrando a responsabilidade de todos, Estado e sociedade, na conquista de um mundo justo e fraterno, um mundo melhor para todas as pessoas.

\section{A TEORIA DA JUSTIÇA DE RAWLS}

John Rawls (2000, p. 12-19) passou sua existência buscando não só determinar qual a melhor definição de uma sociedade justa, mas como alcançá-la de forma prática e afastada da idealização utópica. A definição de justiça faz-se relevante na medida em que é, a partir dessa, que políticas públicas e legislações são desenvolvidas. Para Rawls, o ponto de partida deve ser a imparcialidade, de onde todas as decisões necessariamente convergiriam para a justiça. Para alcançar a imparcialidade real, o filósofo defende que o legislador ou o juiz, a depender do enfoque analisado, sejam trajados com o véu da ignorância, que seria uma espécie de venda que, apesar de permitir que se enxergue adiante, impede que se tenha consciência de si próprio, que se saiba qual sua identificação enquanto membro social.

O importante filósofo acreditava que a sociedade poderia alcançar um bem comum ou ainda a liberdade fundamental (conceito essencial para atingir a justiça equitativa), que na sua concepção significava não submeter essas liberdades a nenhum cálculo de utilidade, 
devendo o véu da ignorância remetido a posição original ser o difusor do parâmetro para estabelecê-las, situação em que nas decisões humanas afastarão o propósito de um interesse particular. Nesse aspecto, o legislador ou juiz, ao não saber seu gênero, sua idade, sua raça ou etnia, sua classe social, dentre tantos outros aspectos que o definem enquanto ser individual, teria idealmente a melhor condição de imparcialidade, visto que, nesse cenário, não teria consciência de qual posição ocuparia após estabelecidas as leis e/ou decisões que dependessem de seu crivo (RAWLS, 2000, p. 19-24).

A Teoria da Justiça por ele formulada é complexa e bem delineada, traçando como caminho para busca da sociedade justa a remissão a posição original, ou seja, um momento hipotético onde as regras sociais ainda não tivessem sido estabelecidas e, para fazê-las, seria utilizado o véu da ignorância, permitindo que a imparcialidade se fizesse presente quando da escolha das proposições a serem adotadas, na exata medida do que seria justo. Isso porque Rawls defende que, sempre que estiver trajando sua humanidade, ou seja, seus valores, suas experiências de vida, o ser humano tende a desvirtuar suas decisões, em um instinto natural e inevitável (RAWLS, 2000, p. 19-24).

Defende ainda que a desigualdade não é um mal por si só, sendo inclusive desejável sob certo aspecto. Para tanto, essa desigualdade precisa ser ao mesmo tempo vantajosa para todos e acessível a todos na medida em que permite as mesmas oportunidades, ficando as diferenças adstritas unicamente a divergência de esforços e interesses individuais e, por outro lado, distribuindo recursos de maneira divergente, o faça no sentido de diminuir as desigualdades, transferindo e aproximando liberdades, oportunidade, renda e riqueza para todos, pois seria um interesse comum no progresso da sociedade e no bem estar social coletivo (RAWLS, 2000, p. 64-72).

Diante dos conceitos formulados por Rawls em busca de uma sociedade justa, é possível perceber que a exclusão do menor sob guarda da proteção previdenciária da pensão por morte se afasta dessa definição na medida em que, além de nitidamente criar uma desigualdade estrutural, não poderia ser, em hipótese alguma, a escolha do legislador se estivesse sob o manto do véu da ignorância, visto que consideraria, nessa hipotética situação, ser possível que ele mesmo fosse afetado estando nessa condição. Isso porque, sem o véu da ignorância para atingir a justiça equitativa estaria a humanidade sempre diante de meros pontos de vista onde, o que é justo para uma determinada pessoa, não o é para outra. 
Dessa forma, a involução da norma previdenciária em debate, durante sua vigência, certamente afastou a República de alcançar uma sociedade justa, criando uma subclasse de filhos equiparados e de famílias, quando na modalidade substituta/extensa, categoria essa que em situação de implementação do risco social morte ao provedor econômico segurado, não teriam qualquer amparo da lei ou do Estado. Vale esclarecer que, como anteriormente demonstrado, o retrocesso a que se refere ocorreu na EC 103/2019. E foi exatamente a preocupação com a inconstitucionalidade de tal norma, a vencedora quando analisado o tema pelo STF, restabelecendo o equilíbrio da proteção social do menor sob guarda.

Nesse sentir, inclusive, muito bem define Ingo Wolfgang Sarlet:

Nesta perspectiva, o fato de os direitos sociais serem considerados autênticos direitos fundamentais e, como tais, levados a sério também na sua condição de direitos subjetivos, tem também servido para imprimir à noção de cidadania um novo contorno e conteúdo, potencialmente mais inclusivo e solidário, o que por si só já justificaria todo o esforço em prol dos direitos sociais e nos serve de alento para seguirmos aderindo ao bom combate às objeções manifestamente infundadas que lhes seguem sendo direcionadas.

A fundamentalidade do direito social afastado pela EC 103/2019, em repetição a outras tentativas de implementar tal política neoliberal, é inegável, visto que previsto inclusive em normativa internacional, sendo acertada a decisão interpretativa proferida pelo STF que, por meio do seu poder de controle, restabeleceu a esperança de retomada do estado de equilíbrio das Garantias Constitucionais do menor sob guarda.

Nesse contexto, a decisão do STF, por maioria, conquistou o estado idealizado pela utilização do véu da ignorância em posição original defendido por Ralws, visto que devolveu ao menor sob guarda a sua dignidade humana, incluindo-o no rol de dependentes previdenciários. Destaca-se, nessa senda, que o Estado deve sempre prezar pelas partes mais vulneráveis para que não haja um colapso social no sentido amplo do termo, o que inegavelmente se aplica ao infante na condição de guarda.

Tanto assim o é que, em um exemplo positivo prático, poder-se-ia citar a Lei 13.954/2019, que abrangeu o Sistema de Proteção Social dos Militares onde, concomitantemente a vigência da exclusão do menor sob guarda do rol de dependentes no RGPS, previu explicitamente a proteção do menor sob guarda no artigo 50, $\S 3^{\circ}$.

Art. 50. $\S 3^{\circ}$ Podem, ainda, ser considerados dependentes do militar, desde que não recebam rendimentos e sejam declarados por ele na organização militar competente: (...)

III - o tutelado ou o curatelado inválido ou menor de 18 (dezoito) anos de idade que viva sob a sua guarda por decisão judicial. 
Nesse contexto verifica-se, inclusive, que dentro do próprio contexto nacional, em sistema de seguridade diverso do Regime Geral, havia consonância com os mandamentos constitucionais e internacionais protetores integrais do menor, reforçando a incoerência da reforma previdenciária a colocá-lo no limbo do "lugar nenhum" de proteção mesmo quando existente a implementação do risco social sob o segurado do qual era dependente econômico. O sentido da seguridade social, conforme nosso posicionamento (BORSIO, 2017), é exatamente conferir justiça social ampla aos integrantes de uma sociedade. Sendo assim, a reedição da norma eliminando o retrocesso pela via do controle judicial se mostrou acertada, fazendo a correta interpretação em nítido diálogo de fontes.

\section{CONCLUSÕES}

O menor é responsabilidade do Estado, da família e da sociedade de um modo geral, conforme preceito Constitucional e internacional da Declaração Universal dos Direitos da Criança, ratificada pelo Brasil.

No que tange ao pertencimento ao rol de dependentes do Regime Geral de Previdência percebe-se uma movimentada alteração quando se trata do menor sob guarda. Ora considerado dependente (o que o foi de forma originária), ora não dependente (sob a justificativa de que a previsão permitia o implemento de fraudes), ora novamente dependente (por uma interpretação judicial em diálogo de fontes com as legislações internacional, constitucional, e ECA enquanto política pública), ora novamente não dependente (quando da Reforma Previdenciária) e, por fim, dependente (ante a decisão do Supremo Tribunal Federal de inconstitucionalidade de interpretação diversa).

Essa instabilidade legal e interpretativa do tema demonstrou um enfoque incorreto quando excluiu o menor da proteção social, pois em momento algum percebe-se que as alterações vislumbraram o interesse de proteção do risco social em evidência e da dignidade da pessoa humana do dependente em análise, mas motivos outros que, na ponderação principiológica se mostram irrelevantes. Partir do pressuposto de negativa de direitos para combate a fraudes é terceirizar a obrigação estatal de controle e imposição da norma, pesando a responsabilidade e o abandono sobre o cidadão, no caso, o menor sob guarda.

As crianças submetidas a guarda vêm de um contexto histórico de conflito lato sensu, precisando, por imposição da igualdade substancial, de maior proteção estatal e, 
exatamente nessa condição foram relegadas, em diversas oportunidades, a invisibilidade da norma e a notória desproteção quando da implementação do risco social morte sob seu guardião, segurado do sistema, especialmente potencializada no cenário pandêmico. Essa involução afastou a legislação brasileira do conceito de Justiça Social, criando um juízo de exclusão, um limbo dos não ditos, dos sem direitos. Isto porque a reforma, ao trazer o termo "exclusivamente" e, não mencionar o menor sob guarda, os colocou em "lugar nenhum" da proteção estatal previdenciária, em nítida divergência dos mandamentos constitucionais e internacionais.

Ao Supremo Tribunal Federal coube o resgate das Garantias Constitucionais por meio do poder de controle que lhe é próprio, aproximando a interpretação do sentido constitucional, em nítido alinhamento a teoria de John Rawls no que se refere a sociedade justa. Nesse contexto o STF retomou os valores humanos básicos da solidariedade, do desapego à cultura do egoísmo desvairado, para buscar o êxtase da Justiça Social, propósito indelével do Estado Democrático de Direito.

\section{REFERÊNCIAS}

AMADO, Frederico. Curso de Direito e Processo Previdenciário. 8a edição. Salvador: Editora JusPodivm, 2016.

ÂMBITO JURÍDICO. O ingresso de crianças e adolescentes em famílias substitutas e as irregularidades ocorridas no processo de adoção. Disponível em: https://ambitojuridico.com.br/edicoes/revista-172/o-ingresso-de-criancas-e-adolescentes-emfamilias-substitutas-e-as-irregularidades-ocorridas-no-processo-de-adocao/. Acesso em: 5 mar. 2021.

BORSIO, Marcelo Fernando. Para uma Previdência Efetivamente Social, além de Bismarck. O Diálogo entre Estados. Constitucionalismo. Trabalho. Seguridade Social e as Reformas Trabalhista e Previdenciária, São Paulo, v. 1, n. 1, p. 528-539, dez./2017.

IBRAHIM, Fábio Zambitte. A PREVIDÊNCIA SOCIAL COMO DIREITO FUNDAMENTAL. Disponível em: https://www.impetus.com.br/artigo/92/a-previdenciasocial-como-direito-fundamental. Acesso em: 22 fev. 2021.

LANDO, Giorge Andre; CUNHA, S. G. C. D; LIMA, M. M. D. S. A Função Social da Família na Promoção do Direito à Educação. Revista Jurídica - UNICURITIBA, Online, v. 
2, n. $43, \quad$ p. $\quad 1, \quad$ jan./2016. Disponível em: http://revista.unicuritiba.edu.br/index.php/RevJur/article/view/1860. Acesso em: 29 set. 2021. LEMOS L. B.; MENEZES R. S.. Pensão por Morte ao menor sob guarda frente à alteração do art.16, $\$ \mathbf{2}^{\circ}$ da Lei $\mathbf{n}^{\circ} \quad \mathbf{8 . 2 1 3} / 1991$. Disponível em: https://dspace.doctum.edu.br/bitstream/123456789/1883/1/PENS\%c3\%83O\%20POR\%20MO RTE\%20AO\%20MENOR\%20SOB\%20GUARDA-\%20FINALIZADO-

\%20Rutilene\%20Souza\%20de\%20Menezes\%202018-1.pdf. 2018. Acesso em: 29 set. 2021.

OIT BRASÍLIA. Lacunas de proteção social nos países em desenvolvimento devem ser fechadas para evitar crises futuras, diz OIT. Disponível em: https://www.ilo.org/brasilia/noticias/WCMS_744774/lang--pt/index.htm. Acesso em: 27 set. 2021.

PLANALTO. CONSTITUIÇÃO DA REPÚBLICA FEDERATIVA DO BRASIL DE 1988. Disponível em: http://www.planalto.gov.br/ccivil_03/constituicao/constituicao.htm. Acesso em: 5 mar. 2021.

PLANALTO. EMENDA CONSTITUCIONAL No 103, DE 12 DE NOVEMBRO DE $2019 . \quad$ Disponível em: http://www.planalto.gov.br/ccivil_03/constituicao/emendas/emc/emc103.htm. Acesso em: 5 mar. 2021.

PLANALTO. LEI No 10.406, DE 10 DE JANEIRO DE 2002 - Código Civil. Disponível em: http://www.planalto.gov.br/ccivil_03/leis/2002/110406compilada.htm. Acesso em: 5 mar. 2021.

PLANALTO. LEI No 13.954, DE 16 DE DEZEMBRO DE 2019. Disponível em: http://www.planalto.gov.br/ccivil_03/_ato2019-2022/2019/lei/L13954.htm. Acesso em: 6 mar. 2021.

PLANALTO. LEI No 8.069, DE 13 DE JULHO DE 1990 - Estatuto da Criança e do Adolescente. Disponível em: http://www.planalto.gov.br/ccivil_03/leis/18069.htm. Acesso em: 5 mar. 2021.

PLANALTO. LEI No 8.213, DE 24 DE JULHO DE 1991 - Planos de Benefícios da Previdência Social. Disponível em: http://www.planalto.gov.br/ccivil_03/leis/18213cons.htm. Acesso em: 5 mar. 2021.

RAWLS, John. UMA TEORIA DA JUSTIÇA. 2. ed. São Paulo: Martin Fontes, 2000. 
SARLET, INGO WOLFGANG. Os Direitos Sociais como Direitos Fundamentais: contributo para um balanço aos vinte anos da Constituição Federal de 1988. Disponível em:

http://files.camolinaro.net/200000421-

9e3879f323/artigo_Ingo_DF_sociais.pdfhttp://www.stf.jus.br/arquivo/cms/processoAudiencia PublicaSaude/anexo/artigo_Ingo_DF_sociais_PETROPOLIS_final_01_09_08.pdf. Acesso em: 6 mar. 2021.

STF. Ação Direta de Inconstitucionalidade 4.878 - Distrito Federal. Disponível em: http://portal.stf.jus.br/processos/downloadPeca.asp?id=15347225924\&ext=.pdf. Acesso em: 27 set. 2021.

STJ.

TEMA

732.

Disponível

em:

https://processo.stj.jus.br/repetitivos/temas_repetitivos/pesquisa.jsp?novaConsulta=true\&tipo _pesquisa=T\&sg_classe=REsp\&num_processo_classe=1411258. Acesso em: 5 mar. 2021.

STJ. Recurso Especial $\mathbf{n}^{\mathbf{0}}$ 1.411.258 - RS (2013/0339203-9). Disponível em: https://processo.stj.jus.br/processo/revista/documento/mediado/?componente=ATC\&sequenci $\mathrm{al}=53725109 \&$ num_registro=201303392039\&data=20180221\&tipo=51\&formato=PDF.

Acesso em: 28 set. 2021.

UNICEF. Convenção sobre os Direitos da Criança. Disponível em: https://www.unicef.org/brazil/convencao-sobre-os-direitos-da-crianca. Acesso em: 5 mar. 2021. 